\title{
Rochas metamáficas associadas ao arco magmático de Goiás na região de Pontalina - GO
}

\author{
Guillermo Rafael Beltran Navarro ${ }^{1}$, Antenor Zanardo ${ }^{2}$ \& Luiz Sérgio Amarante Simões ${ }^{2}$
}

\begin{abstract}
Resumo Corpos de rochas metamáficas de dimensões variadas ocorrem intercalados em gnaisses e rochas metassedimentares, e estão associados ao Arco Magmático de Goiás na região de Pontalina. Dados químicos mostram que as rochas metamáficas são de origem magmática e que apresentam afinidade toleítica subalcalina a alcalina, similaridade com basaltos enriquecidos de cadeias meso-oceânicas (E-MORB) e em parte com basaltos de arco de ilha (IAB). Dados isotópicos e geoquímicos sugerem que essas rochas são neoproterozóicas $\left(\mathrm{T}_{\mathrm{DM}}=1,0\right.$ a 1,2 Ga) associadas à subducção de crosta oceânica e, conseqüente, geração de arco de ilhas.
\end{abstract}

Palavras-chave: arco magmático de Goiás, Faixa Brasília, geoquímica, rochas metamáficas.

\begin{abstract}
Metamafic rocks associated to the Goiás magmatic arc in the region Pontalina - GO. In the Pontalina region, Goiás, many metamafic bodies presenting various sizes are associated to gneiss and metasedimentary rocks occur within the Goiás Magmatic Arc. Geochemical data shows that the metamafic rocks are of magmatic origin, present alkaline to sub alkaline compositions and tholeiitic affinities. The signatures in relation to the incompatible elements may be compared to that of the enriched mid ocean ridge basalt (E-MORB) or to that of island arc basalt (IAB). Isotopic studies indicate Neoproterozoic ages with $\mathrm{T}_{\mathrm{DM}}$ between 1.0 and $1.2 \mathrm{Ga}$ and possibly they are related to oceanic crust subduction and formation of island arcs.
\end{abstract}

Keywords: Goiás magmatic arc, Brasília belt, geochemistry, metamafic rocks.

INTRODUÇÃo O Arco Magmático de Goiás (Pimentel \& Fuck 1991, 1992) ocorre na porção oeste da Faixa Brasília, e divide-se em dois segmentos. O primeiro com direção NE-SW que aflora na região de Mara Rosa-Porangatu e o outro com direção aproximadamente NW-SE que aflora na região de Bom Jardim a Firminópolis, estendendo-se até a região de Pontalina-Burití Alegre (Pimentel et al. 2000a, b). Esse arco magmático é constituído por rochas metaplutônicas associadas a faixas de rochas metassedimentares e metavulcânicas; que apresentam características geoquímicas e isotópicas similares a arcos de ilhas modernos intraoceânicos e cordilheiranos (Pimentel et al. 2004).

Na região de Pontalina, as rochas associadas ao Arco Magmático de Goiás são reunidas sob a denominação informal de "Terrenos Gnáissico-Metassedimentares", que é subdividido em duas seqüências: seqüência metassedimentar e seqüência gnáissica (Fig. 1). A seqüência metassedimentar é constituída por gnaisses bandados quartzosos, muscovita gnaisses, epidoto-biotita-muscovita gnaisses, com intercalações de muscovita quartzito (às vezes feldspáticos), quartzito ferruginoso (magnetita-muscovita quartzito) e xistos (granadabiotita xisto, muscovita xisto, biotita-muscovita xisto e magnetita-muscovita xisto).

A seqüência gnáissica é composta por conjunto de rochas representadas por hornblenda-biotita gnaisses, biotita gnaisses, granada-biotita gnaisses e muscovita gnaisses. Esses gnaisses apresentam bandamento composicional marcante, localmente dobrado, de espessuras variadas, granulação média a grossa e foliação conspícua. Nas duas seqüências aparecem corpos de rochas metaultramáficas (clorita xisto, talco xisto e serpentinitos), sendo o mais representativo aquele que constitui o Morro Dois Irmãos.

Rochas metamáficas ocorrem intercaladas como lentes e camadas tanto na seqüência gnáissica como na metassedimentar, sendo bem menos freqüentes nessa última unidade.

As associações minerais das rochas metamáficas, relacionadas ao pico do metamorfismo, são típicas da fácies anfibolito, caracterizadas pela presença de hornblenda/(cummingtonita)+andesina/labradorita, granada+hornblenda/(cummingtonita)+andesina/labradorita, sendo o rutilo e ilmenita os principais óxidos associados. Uma única amostra apresenta a paragênese mineral hornblenda+andesina/labradorita+clinopiroxênio indicando que, localmente condições de temperatura mais elevada foram alcançadas. Essas associações evidenciam que as temperaturas mínimas estiveram entre $600^{\circ} \mathrm{C}$ a $650^{\circ} \mathrm{C}$, em condições de pressão superiores a 6 kbar. O retrometamorfismo é caracterizado pela presença de minerais que sugerem reequilíbrio em condições de fácies anfibolito a xisto verde, envolvendo a transformação de: granada e anfibólio para biotita e clorita; surgimento de ilmenita e titanita a partir do titânio e cálcio liberado nas reações retrometamórficas; aparecimento de epidoto e mica branca intersticial e sobre 


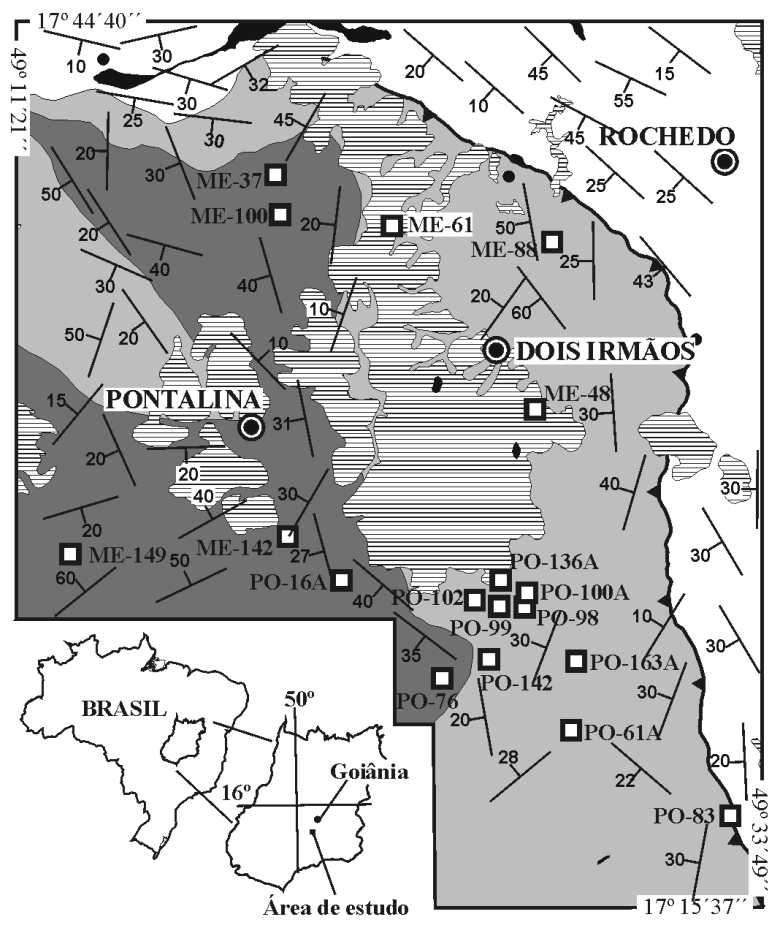

LEGENDA

Dep. Quaternários/Terciários

Metaultramáficas

Terrenos Gnáissicos-Metassedimentares

Seqüência Metassedimentar

Seqüência Gnáissica

Grupo Araxá

Figura 1 - Mapa geológico esquemático da região de Pontalina, mostrando a localização das amostras analisadas.

o plagioclásio; coroas de albita límpidas na borda do plagioclásio saussuritizado; e a formação de actinolita junto à borda de hornblenda.

Uma foliação principal ( $\mathrm{Sn}$ ), de caráter regional, é observada na região. Essa apresenta direção geral $\mathrm{N}-\mathrm{S}$ a NNW/SSE e baixo a médio ângulo de mergulho para W. No extremo norte da área essa foliação está disposta, aproximadamente, na direção E-W, com mergulho baixo a médio para $S(S n=214 / 17)$. Localmente, observa-se uma foliação anterior (Sn-1), paralela ao bandamento composicional, transposta pela foliação principal. A lineação mineral e/ou de estiramento apresenta baixo ângulo de mergulho para $\mathrm{W}$ e possui direção geral E-W (256/09). Os indicadores cinemáticos apontam sistematicamente transporte de topo para E.

\section{PETROGRAFIAE QUÍMICA MINERALDAS RO-} CHAS METAMÁFICAS As rochas metamáficas (anfibolitos e anfibólio xisto) ocorrem na forma de corpos lenticulares de espessuras decimétricas a decamétricas e extensões métricas a hectométricas, orientados paralelamente ao bandamento das rochas encaixantes. Exibem granulação média a grossa, cor verde escura, textura nematoblástica a decussada, com ou sem domínios granoblásticos, e estrutura xistosa, localmente, com bandamento descontínuo marcado por pequenas lentes quartzo/feldspáticas. São constituídos principalmente por anfibólio (70-95\%), plagioclásio (0-30\%) e quartzo $(0-15 \%)$, podendo ocorrer ainda como minerais essenciais granada $(0-10 \%)$, biotita $(0-20 \%)$ e tremolita/actinolita $(0-15 \%)$. Como minerais acessórios e ou secundários encontra-se apatita, rutilo, titanita, zircão, opacos, clorita, allanita e epidoto.

A hornblenda, o anfibólio mais freqüente, é anedral a subedral e apresenta pleocroísmo forte com cor castanha, verde oliva a verde azulada em " $\gamma$ ", evidenciando variação composicional e dimensões médias submilimétricas $(0,4$ a $0,6 \mathrm{~mm})$. Pode constituir porfiroblastos e, às vezes, poiquiloblastos (inclusões retas ou não de plagioclásio, quartzo, rutilo, epidoto e opacos). A cummingtonita aparece em proporções inferiores a $1 \%$, normalmente, no núcleo das hornblendas constituindo lamelas de exsolução, ou na matriz, formando pequenos cristais anedrais $(<0,2 \mathrm{~mm})$ dispersos. A actinolita, produto da transformação retrometamórfica de hornblenda, é anedral a subedral e submilimétrica. Análises de química mineral em cristais de anfibólio relacionados ao ápice metamórfico mostram composições dominantemente cálcicas, e são classificados como tschermakita-magnésio hornblenda e como magnésiohastingsita, com razões $\left(\mathrm{Mg} / \mathrm{Mg}+\mathrm{Fe}^{2+}\right)$ variando entre 0,5 e 0,8 (Fig. 2). Anfibólios do grupo Fe-Mn-Mg, classificados como cummingtonita, ocorrem, subordinadamente, exibindo razões $\left(\mathrm{Mg} / \mathrm{Mg}+\mathrm{Fe}^{2+}\right)$ variando entre 0,775 e 0,736 .

O plagioclásio ocorre intersticialmente ao anfibólio, formando agregados lenticulares, ou como vênulas descontínuas em associação com quartzo, epidoto e granada definindo bandamento composicional. Os cristais de plagioclásio são submilimétricos e, localmente, apresentam extinção ondulante. A albita é produto de retrometamorfismo constituindo coroas em cristais de plagioclásio mais cálcico, ou como pequenos cristais anedrais dispersos na lâmina junto a anfibólio. As aná- 


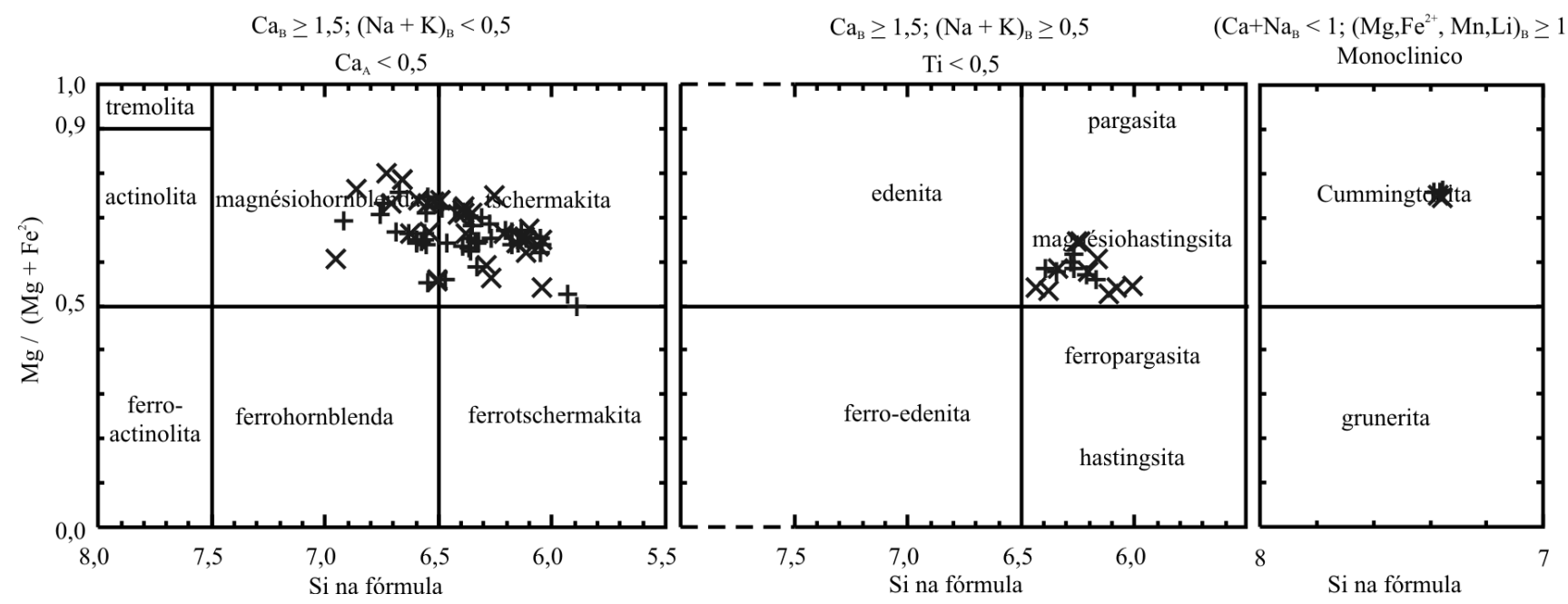

Figura 2 - Classificação do anfibólio analisado segundo a classificação de Leake et al. (1997).

lises químicas de cristais de plagioclásio mostram que a composição dos plagioclásios varia de oligoclásio a bytownita $\left(\mathrm{an}_{13-85}\right)$, predominando composições de labradorita (Fig. 3), e não mostram claro zoneamento químico, apenas porções irregulares de composições diferentes.

A granada é subedral a anedral, ocorre dispersa, podendo constituir porfiroblastos e poiquiloblastos com inclusões de rutilo, ilmenita, quartzo, epidoto e plagioclásio. Estudos de química mineral de alguns cristais de granada analisados, por microssonda eletrônica, mostram que a granada apresenta composição rica na molécula de almandina $\left(\mathrm{Alm}_{49,6-69,1}\right)$, seguida por piropo $\left(\mathrm{Py}_{15,4-28,3}\right)$ e grossulária $\left(\mathrm{Grs}_{6,6-18,2}^{49,6-69,1}\right)$, apresentando baixos conteúdos na molécula de espessartita $\left(\mathrm{Sps}_{0,9-5,5}\right)$, andra$\operatorname{dita}\left(\right.$ And $\left._{0,0-5,0}\right)$ e uvarovita $\left(\mathrm{Uva}_{0,0-0,1}\right)$.

Biotita, clorita e mica branca constituem cristais subedrais, dispostos de maneira orientada segundo a foliação e são produtos do retrometamorfismo, oriundos de anfibólio, plagioclásio e granada. $\mathrm{O}$ epidoto é anedral a subedral, submilimétrico, e ocorre parcialmente orientado. Apresenta coloração verde pálido a amarelo, podendo em algumas rochas ultrapassar $5 \%$ do volume, constituindo epidoto anfibolito e epidoto-anfibólio xisto. A titanita é comum, podendo em alguns casos perfazer cerca de 4\% da área da lâmina, é anedral a subeuedral, ocorre dispersa, localmente, marcando trilhas ou envolvendo rutilo e as dimensões de seus cristais nunca ultrapassam $0,3 \mathrm{~mm}$. Os outros minerais (apatita, magnetita, ilmenita, allanita, dentre outros) ocorrem dispersos pela rocha, com granulação fina e formas anedrais a euedrais.

Transformações hidrotermais são observadas em algumas amostras, principalmente em amostras da seqüência metassedimentar. Nessas amostras observam-se intensa albitização do plagioclásio mais cálcico, e intensa epidotização. $\mathrm{O}$ epidoto resultante desse processo é verde-amarelado, constituindo cristais euedrais a sub-eudrais e ocorrem, às vezes, em veios que cortam as rochas ou intersticialmente ao anfibólio

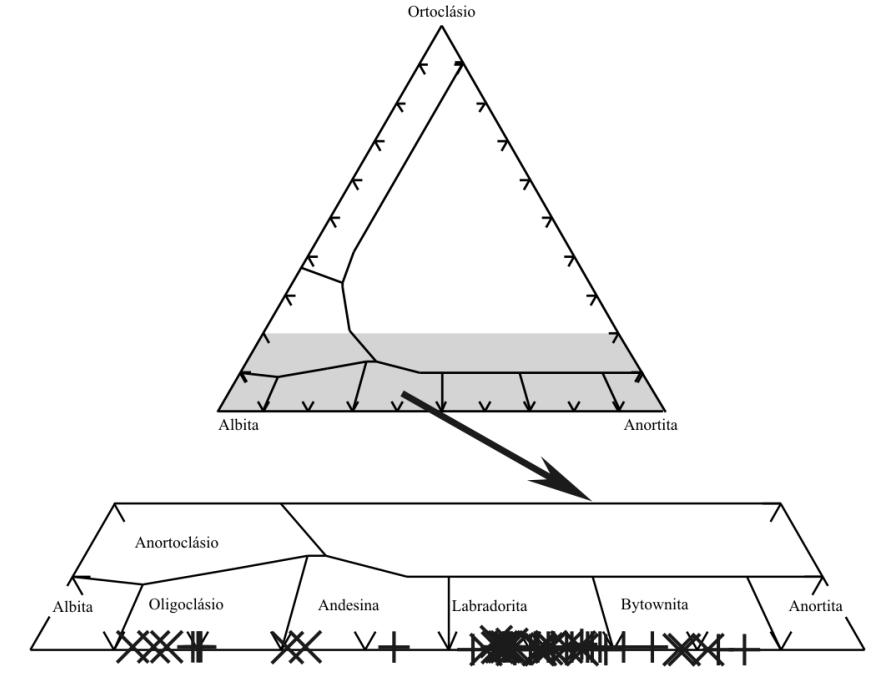

Figura 3 - Classificação do plagioclásio analisado.

e plagioclásio. Biotitização parcial ou total de algumas rochas metamáficas é observada principalmente junto ao contato com as encaixantes e em algumas ocorrências de pequena espessura $(<0,50 \mathrm{~cm})$. A formação de muscovita, intersticialmente ao plagioclásio cálcico e anfibólio, também pode estar relacionada à passagem de fluidos (hidrotermalismo) durante a evolução tectônica. Em algumas ocorrências de rochas metamáficas constatou-se a entrada de material quartzo feldspático, constituindo lentes descontínuas e ou finas camadas conferindo aspecto bandado à rocha.

\section{GEOQUÍMICA DAS ROCHAS METAMÁFI-}

CAS As amostras selecionadas para análise química (rocha total) e para estudos litogeoquímicos foram analisadas no Laboratório de Geoquímica (Labogeo) do Departamento de Petrologia e Metalogenia - DPM do Instituto de Geociências e Ciências Exatas (IGCE), 
UNESP - Campus de Rio Claro. As análises de elementos maiores $\left(\mathrm{SiO}_{2}, \mathrm{TiO}_{2}, \mathrm{Al}_{2} \mathrm{O}_{3}, \mathrm{Fe}_{2} \mathrm{O}_{3 \mathrm{~T}}, \mathrm{MnO}, \mathrm{MgO}\right.$, $\mathrm{CaO}, \mathrm{Na}_{2} \mathrm{O}, \mathrm{K}_{2} \mathrm{O}, \mathrm{P}_{2} \mathrm{O}_{5}$ e o LOI) e traço ( $\mathrm{Ba}, \mathrm{Cr}, \mathrm{Cu}$, $\mathrm{Nb}, \mathrm{Ni}, \mathrm{Rb}, \mathrm{Sr}, \mathrm{Y}$ e $\mathrm{Zr}$ ) foram feitas pelo método de Fluorescência de Raios X (FRX) e as dos Elementos Terras Raras (ETR - La, Ce, Nd, Sm, Eu, Gd, Dy, Er, $\mathrm{Yb}, \mathrm{Lu})$ pelo método de Espectrometria de Emissão Atômica, com Fonte de Plasma Acoplado Indutivamente (ICP-AES). Para a manipulação dos dados geoquímicos e construção dos diagramas utilizou-se o software MinPet (Richard 1985).

A abertura química de amostras para análise isotópica $\mathrm{Sm}-\mathrm{Nd}$ foram feitas no Laboratório de Geoquímica Isotópica da UNESP/Rio Claro. A separação do $\mathrm{Rb}$ e $\mathrm{Sr}$ dos ETRs dos outros constituintes das amostras foi feita em colunas primárias (condicionada com $20 \mathrm{~mL}$ de $\mathrm{HCl}$ de 2,5 N) carregadas com resina de troca catiônica BIO-RAD AG50W-X8 AG50W-X8 (200-400 mesh). Após várias etapas de lixiviação com $\mathrm{HCl} 2,5$ $\mathrm{N}$, a coleta dos ETRs nessas colunas foi realizada com $\mathrm{HCl} 6 \mathrm{~N}$ em savillex de teflon. A separação do Sm e do $\mathrm{Nd}$ dos demais elementos terras raras foi realizada em colunas secundárias (condicionadas com $\mathrm{HCl} 0,18 \mathrm{~N}$ ) carregada com resina do tipo LN SPEC (resina líquida HDEHP-ácido di-(etilhexil) fosfórico) impregnada em pó de tefron de 200-400 mesh. Após várias etapas de lixiviação com $\mathrm{HCl} 0,18 \mathrm{~N}$ para retirada dos demais elementos terras raras, coleta-se o $\mathrm{Nd}$ com $\mathrm{HCl} 0,18 \mathrm{~N}$ e o $\mathrm{Sm}$ com $\mathrm{HCl}$ 0,5 $\mathrm{N}$ em savillex e teflon (Hackspacher et al. 2004). Depois de secas em placa aquecedora as amostras foram analisadas em Espectrômetro de Massa por ionização termal (TIMS) da marca Finningan MAT262 multi-coletor do Laboratório de Geocronologia da Universidade de Brasília.

Como as rochas estudadas foram metamorfisadas na fácies anfibolito, utilizou-se o diagrama $\mathrm{Na}_{2} \mathrm{O}+\mathrm{K}_{2} \mathrm{O}$ vs. $\mathrm{Na}_{2} \mathrm{O} / \mathrm{K}_{2} \mathrm{O}$ (Miyashiro 1975) para avaliar se ocorreram modificações químicas significativas no quimismo original dos protólitos das rochas analisadas (Fig. 4). Esse diagrama indica que algumas amostras podem ter sofrido alteração química, principalmente em relação a $\mathrm{Na}_{2} \mathrm{O}$ e $\mathrm{K}_{2} \mathrm{O}$.

A ausência de estruturas, mineralogia ou texturas primárias, em função da intensa recristalização ocorrida durante a evolução tectono-metamórfica, não permitiu a definição da origem das rochas. Dessa forma, a natureza do protólito dessas rochas foi caracterizada utilizando-se o diagrama $\mathrm{Ni} v$ s. $\mathrm{Zr} / \mathrm{Ti}$ (Winchester et al. 1980) e pelo diagrama de Leake (1964), que utiliza os parâmetros e/ou números de Niglli (1954) (Fig. 5).

As amostras com indícios de alteração química (Fig. 4, amostras ME-142, PO-98, PO-102 e PO-163) e que plotam no campo de origem sedimentar (Fig. 5, amostras ME-1-61 e PO-16A) foram excluídas das discussões subseqüentes, embora, em alguns casos, mesmo quando há evidências de alterações químicas de alguns elementos (geralmente álcalis), nem sempre os elementos menos móveis (como REE, Y, dentre outros) são afetados significativamente, o que permite discussões petrogenéticas.

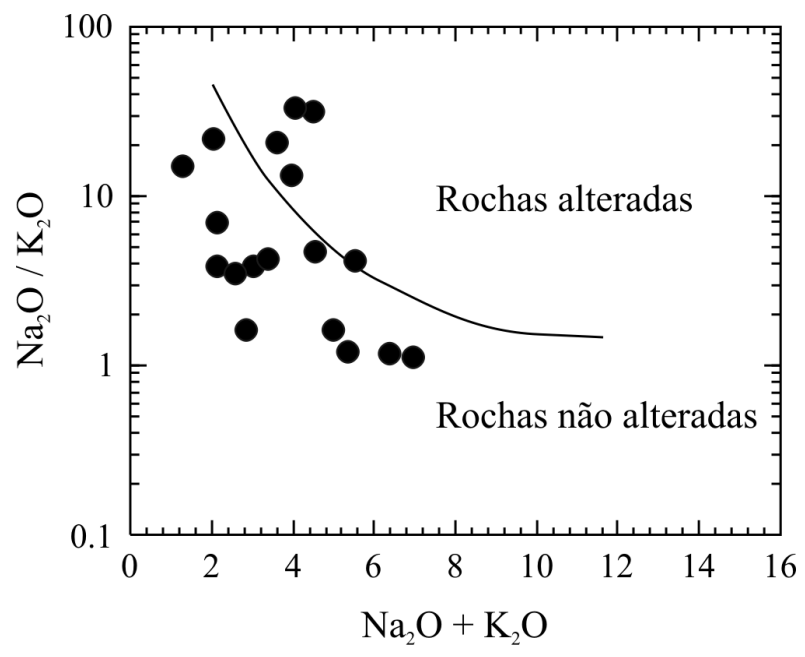

Figura 4 - Diagrama de Miyashiro (1975) para discriminação de rochas que sofreram alteração por processos pós-magmáticos.

A)

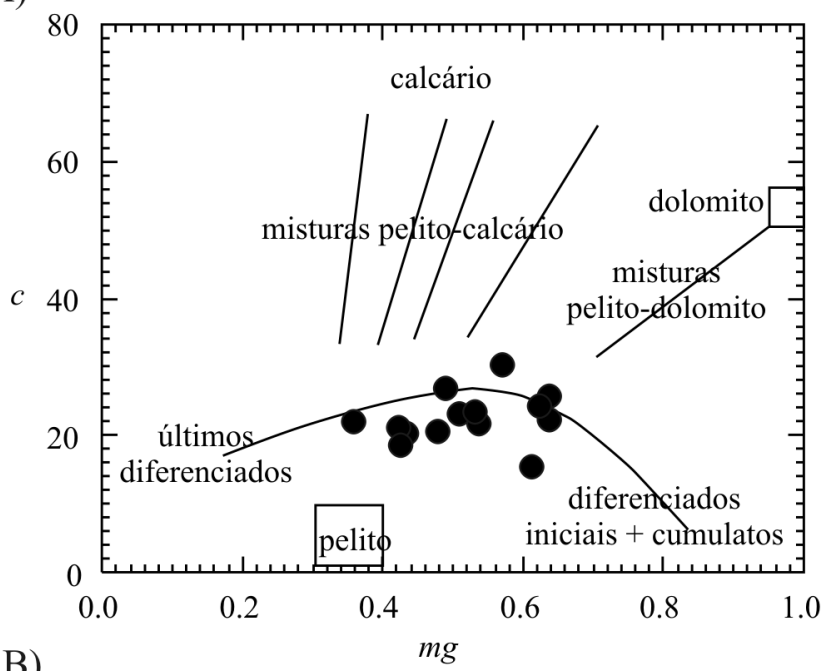

B)

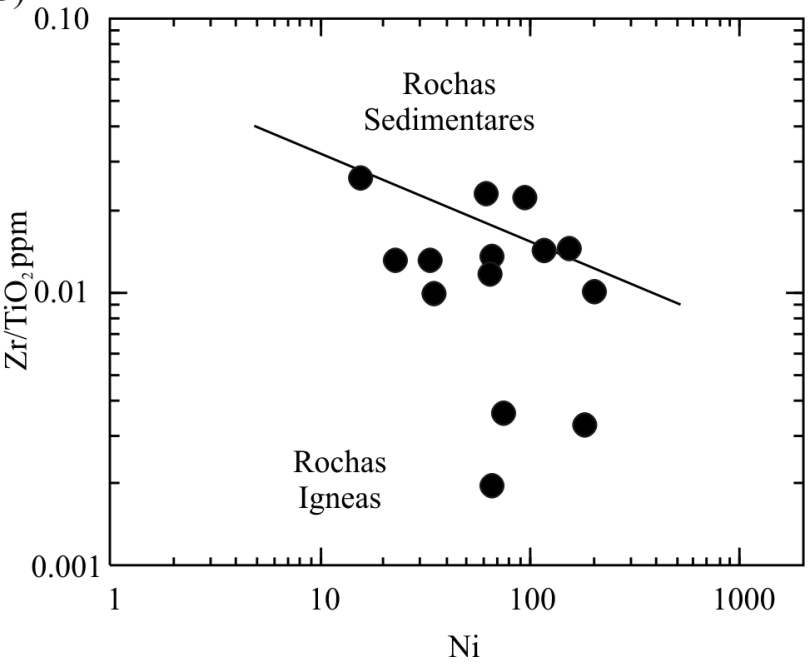

Figura 5 - Diagramas para caracterização química da origem dos protólitos de rochas metamáficas. (A) Diagrama de Winchester et al. (1980) e (B) Diagrama de Leake (1964) onde $\underline{M g}$ e $\underline{c}$ correspondem aos parâmetros de Niggli (1954). 
Quimicamente, a maioria das amostras apresenta natureza básica, predominando composições de basaltos sub-alcalinos e basaltos andesíticos (Fig. 6). Os diagramas álcalis vs sílica (Irvine \& Baragar 1971) e AFM (Irvine \& Baragar 1971) mostram que as rochas metamáficas analisadas apresentam afinidade toleítica subalcalina a alcalina (Fig. 7).

Os resultados analíticos para elementos maiores das rochas metamáficas analisadas são apresentados na tabela 1 . O conjunto de amostras analisadas, não mostra trends ou grupos bem definidos, apresentando grande dispersão nos conteúdos dos elementos analisados (Fig. 8). As rochas apresentam baixas concentrações de álcalis $\left(\mathrm{Na}_{2} \mathrm{O}=1,19-4,46\right.$ e $\left.\mathrm{K}_{2} \mathrm{O}=0,09-3,33\right)$, de $\mathrm{MnO}$ $(<0,53 \%)$ e de $\mathrm{P}_{2} \mathrm{O}_{5}(<0,42 \%)$. O conteúdo de $\mathrm{MgO}$ varia de 3,26 a 10,75\%, o de $\mathrm{Fe}_{2} \mathrm{O}_{3 \mathrm{~T}}$ varia de 7,61 a $17,76 \mathrm{e}$ o de $\mathrm{CaO}$ entre 5,67 e 12,14\%. Em relação aos elementos traço (Tab. 2, Fig. 8) os diagramas de variação em relação à $\mathrm{MgO}$ apresentam, como observado também em relação aos elementos maiores, uma grande dispersão, não exibindo tendências bem marcadas.

O conteúdo e padrão de distribuição de elementos terras raras das amostras analisadas (Tab. 3), quando normalizadas pelo condrito (Taylor \& MacLennan 1985), permitem separar as amostras em dois grupos (Fig. 9).

O primeiro (grupo 1) apresenta um padrão de ETRL (elementos terras raras leves) e ETRP (elementos terras raras pesados) variando entre 6 a 26 vezes o valor do condrito, apresentando padrão de distribuição subhorizontal com leve enriquecimento em ETRL e ETRP (razões $\mathrm{La}_{\mathrm{N}} / \mathrm{Eu}_{\mathrm{N}}=1,25-1,4, \mathrm{Gd}_{\mathrm{N}} / \mathrm{Lu}_{\mathrm{N}}=1,18$ 2,02, $\left.\mathrm{La}_{\mathrm{N}} / \mathrm{Lu}_{\mathrm{N}}=1,48-3,02\right)$, semelhantes a basaltos tipo E-MORB (basaltos enriquecidos de cadeia meso oceânica) e IAB (basaltos de arco de ilha). O segundo (grupo 2) apresenta padrão de distribuição que varia de
A)

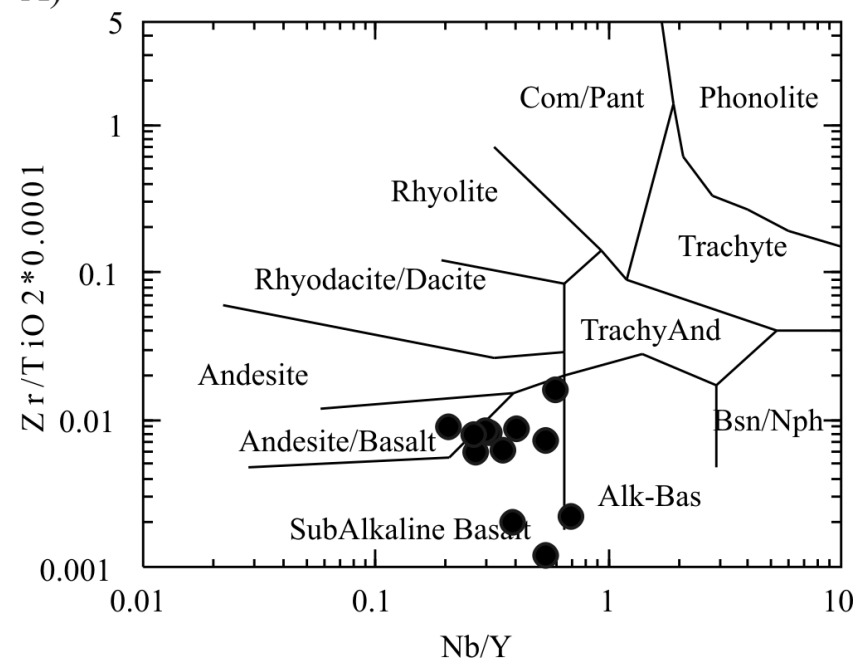

B)

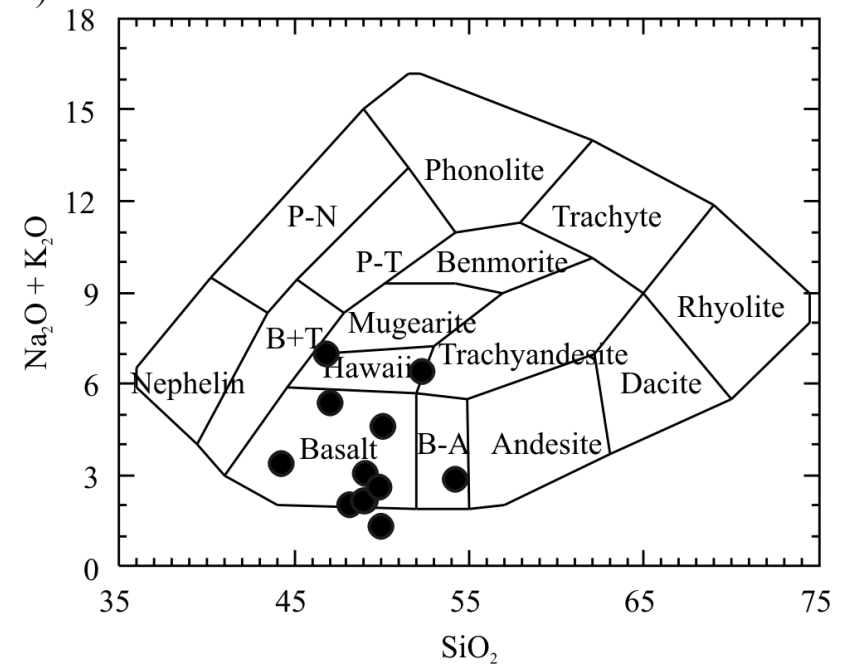

Figura 6 - Composição das amostras da área de estudo. (A) Diagrama de Winchester \& Floyd (1977). (B) Diagrama de Cox et al. (1979).
A)

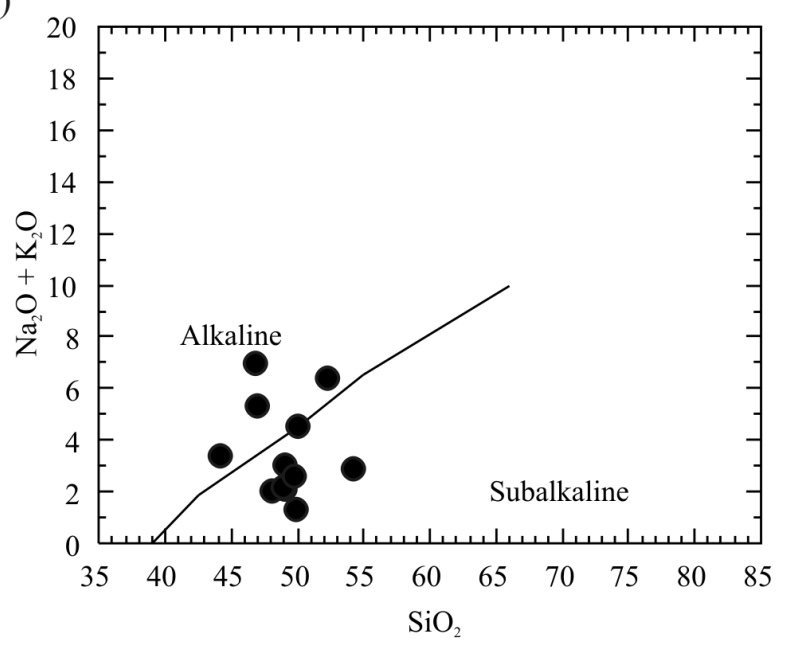

B)

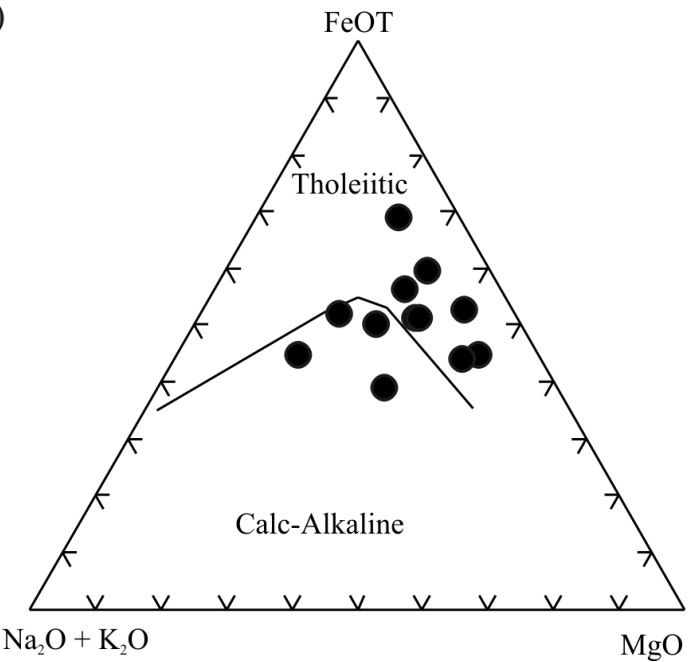

Figura 7 - (A) Diagrama de álcalis vs. sílica (Irvine \& Baragar 1971) ilustrando a natureza subalcalina das amostras. (B) Diagrama AFM (Irvine \& Baragar 1971, $\mathrm{A}=\mathrm{Na}_{2} \mathrm{O}+\mathrm{K}_{2} \mathrm{O} ; \mathrm{F}=\mathrm{FeO}_{T}, \mathrm{M}=$ $\mathrm{MgO}$ ) mostrando o caráter toleitico das amostras analisadas. 
Tabela 1 - Teores de elementos maiores (em \%) das rochas metamáficas da região de Pontalina.

\begin{tabular}{l|c|c|c|c|c|c|c|c|c|c|c|c}
\hline Amostra & $\mathrm{SiO}_{2}$ & $\mathrm{TiO}_{2}$ & $\mathrm{Al}_{2} \mathrm{O}_{3}$ & $\mathrm{Fe}_{2} \mathrm{O}_{3}$ & $\mathrm{MnO}$ & $\mathrm{MgO}$ & $\mathrm{CaO}$ & $\mathrm{Na}_{2} \mathrm{O}$ & $\mathrm{K}_{2} \mathrm{O}$ & $\mathrm{P}_{2} \mathrm{O}_{5}$ & LOI & Total \\
\hline ME-37 & 49.88 & 1.63 & 14.94 & 11.35 & 0.14 & 5.64 & 10.17 & 3.66 & 0.79 & 0.45 & 1.75 & 100.40 \\
\hline ME-48(anf) & 49.26 & 1.20 & 16.12 & 10.71 & 0.18 & 9.62 & 9.06 & 1.99 & 0.57 & 0.15 & 2.03 & 100.89 \\
\hline ME-88 & 53.87 & 1.15 & 15.93 & 11.05 & 0.09 & 6.53 & 7.68 & 1.76 & 1.09 & 0.15 & 1.02 & 100.32 \\
\hline ME-100anf & 46.71 & 1.45 & 17.03 & 11.53 & 0.09 & 9.27 & 6.48 & 3.65 & 3.32 & 0.28 & 0.96 & 100.75 \\
\hline ME-142 & 45.33 & 1.65 & 17.99 & 11.86 & 0.10 & 8.78 & 9.33 & 3.42 & 0.17 & 0.17 & 1.68 & 100.49 \\
\hline ME-149DI & 43.64 & 2.43 & 19.07 & 14.30 & 0.08 & 6.70 & 9.04 & 2.69 & 0.64 & 0.08 & 1.61 & 100.27 \\
\hline PO-16A & 53.43 & 0.79 & 16.69 & 7.51 & 0.08 & 6.36 & 8.66 & 3.02 & 1.90 & 0.23 & 1.64 & 100.31 \\
\hline PO-61A & 51.80 & 1.63 & 20.80 & 8.57 & 0.11 & 3.23 & 6.08 & 3.40 & 2.94 & 0.47 & 1.07 & 100.10 \\
\hline PO-76 & 49.78 & 0.63 & 18.42 & 10.20 & 0.15 & 6.94 & 12.10 & 1.19 & 0.08 & 0.15 & 0.87 & 100.51 \\
\hline PO-83 & 48.22 & 1.97 & 18.38 & 10.99 & 0.14 & 6.41 & 8.88 & 2.37 & 0.62 & 0.23 & 1.92 & 100.12 \\
\hline PO-98 & 51.00 & 1.05 & 15.99 & 12.33 & 0.15 & 6.52 & 8.97 & 3.67 & 0.28 & 0.10 & 0.86 & 100.93 \\
\hline PO-99 & 48.17 & 0.80 & 13.35 & 11.31 & 0.52 & 10.55 & 11.06 & 1.55 & 0.43 & 0.41 & 1.86 & 100.00 \\
\hline PO-100A & 48.54 & 2.07 & 18.67 & 14.26 & 0.23 & 6.69 & 8.04 & 1.96 & 0.09 & 0.24 & 0.03 & 100.79 \\
\hline PO-102 & 53.89 & 1.78 & 14.48 & 14.85 & 0.13 & 4.65 & 5.68 & 4.38 & 0.14 & 0.22 & 0.38 & 100.58 \\
\hline PO-136A & 49.26 & 2.26 & 15.07 & 17.86 & 0.25 & 5.09 & 8.41 & 1.89 & 0.27 & 0.20 & 0.31 & 100.89 \\
\hline PO-142 & 46.25 & 1.05 & 21.96 & 11.36 & 0.16 & 4.24 & 8.03 & 2.84 & 2.41 & 0.10 & 2.41 & 100.81 \\
\hline PO-163A & 47.39 & 2.97 & 16.05 & 14.99 & 0.12 & 5.48 & 7.71 & 3.91 & 0.12 & 0.67 & 0.61 & 100.02 \\
\hline ME-1-61 & 52.90 & 1.03 & 19.51 & 9.59 & 0.09 & 3.73 & 6.94 & 4.44 & 1.08 & 0.22 & 0.89 & 100.43 \\
\hline
\end{tabular}

Estes valores foram recalculados em base anidra. (recalculados para 100\%)
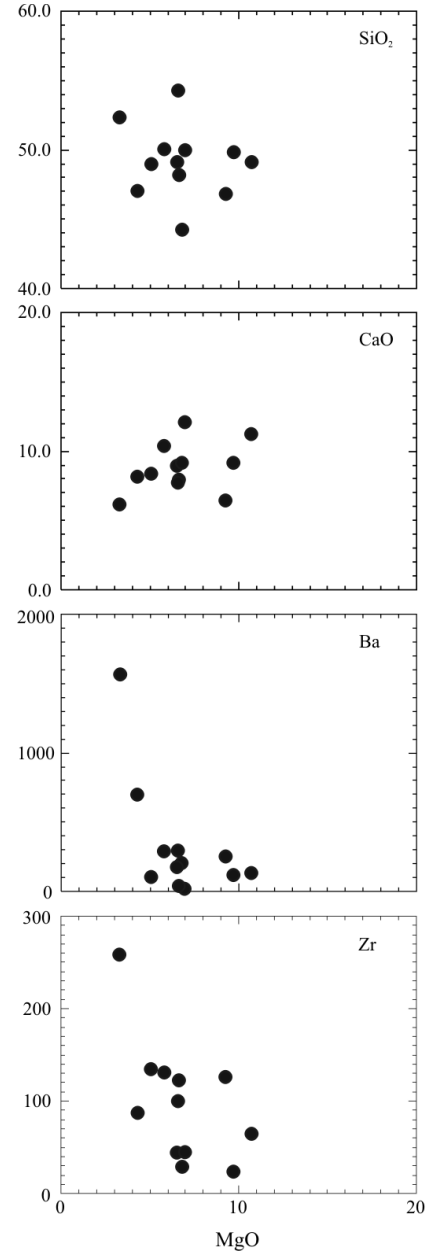
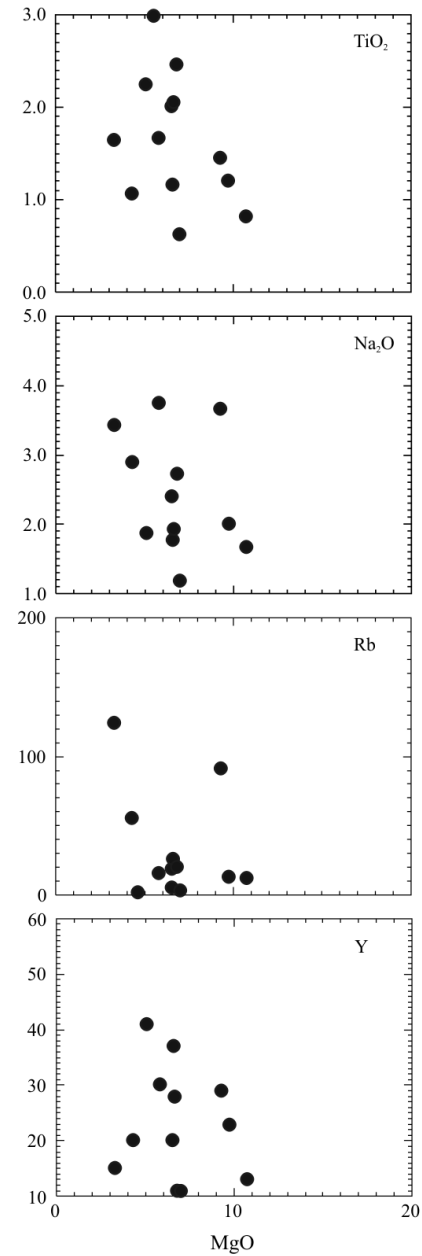
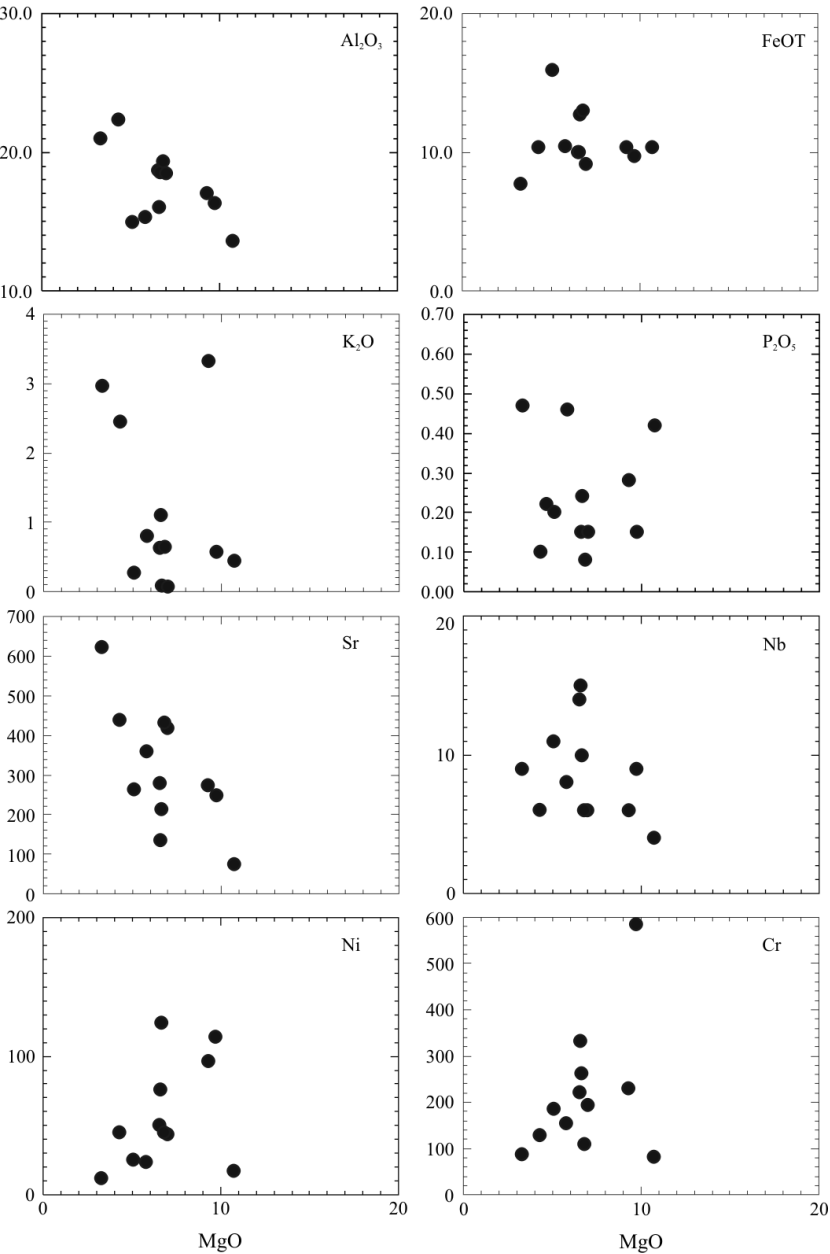

Figura 8 - Diagramas binários de elementos maiores e traços $x \mathrm{MgO}$, mostrando a variação da composição das amostras. 
Tabela 2 - Teores de elementos traço (em ppm) das rochas metamáficas da região de Pontalina.

\begin{tabular}{l|c|c|c|c|c|c|c|c|c}
\hline Amostra & $\mathrm{Ba}$ & $\mathrm{Rb}$ & $\mathrm{Sr}$ & $\mathrm{Y}$ & $\mathrm{Zr}$ & $\mathrm{Nb}$ & $\mathrm{Cu}$ & $\mathrm{Ni}$ & $\mathrm{Cr}$ \\
\hline ME-37 & 287 & 16 & 358 & 30 & 131 & 8 & 8 & 24 & 155 \\
\hline ME-48(anf) & 114 & 13 & 248 & 23 & 24 & 9 & 584 & 114 & 584 \\
\hline ME-88 & 292 & 26 & 135 & 37 & 100 & 15 & 31 & 76 & 333 \\
\hline ME-100anf & 255 & 91 & 274 & 29 & 126 & 6 & 58 & 97 & 231 \\
\hline ME-142 & 65 & 2 & 288 & 34 & 113 & 6 & 67 & 92 & 170 \\
\hline ME-149DI & 199 & 20 & 432 & 11 & 29 & 6 & 63 & 45 & 109 \\
\hline PO-16A & 1003 & 40 & 614 & 20 & 107 & 7 & 28 & 62 & 185 \\
\hline PO-61A & 1591 & 124 & 623 & 15 & 258 & 9 & 29 & 12 & 88 \\
\hline PO-76 & 18 & 3 & 418 & 11 & 44 & 6 & 90 & 44 & 194 \\
\hline PO-83 & 171 & 19 & 278 & 20 & 44 & 14 & 47 & 50 & 222 \\
\hline PO-98 & 86 & 5 & 199 & 28 & 62 & 5 & 28 & 29 & 117 \\
\hline PO-99 & 130 & 12 & 75 & 13 & 65 & 4 & 4 & 17 & 83 \\
\hline PO-100A & 39 & 3 & 213 & 28 & 123 & 10 & 4 & 124 & 263 \\
\hline PO-102 & 81 & 2 & 256 & 36 & 107 & 6 & 24 & 14 & 139 \\
\hline PO-136A & 101 & 3 & 264 & 41 & 134 & 11 & 105 & 25 & 186 \\
\hline PO-142 & 699 & 55 & 439 & 20 & 87 & 6 & 4 & 45 & 129 \\
\hline PO-163A & 337 & 3 & 464 & 54 & 249 & 12 & 22 & 8 & 90 \\
\hline ME-1-61 & 265 & 21 & 517 & 24 & 141 & 8 & 173 & 42 & 130 \\
\hline
\end{tabular}

Tabela 3 - Teores de elementos terras raras (em ppm) das rochas metamáficas da região de Pontalina.

\begin{tabular}{l|r|r|r|r|r|r|r|r|r|r}
\hline Amostra & $\mathrm{La}$ & $\mathrm{Ce}$ & $\mathrm{Nd}$ & $\mathrm{Sm}$ & $\mathrm{Eu}$ & $\mathrm{Gd}$ & $\mathrm{Dy}$ & $\mathrm{Er}$ & $\mathrm{Yb}$ & $\mathrm{Lu}$ \\
\hline ME-37 & 26.90 & 63.00 & 34.20 & 7.17 & 2.11 & 6.17 & 5.16 & 2.72 & 2.22 & 0.36 \\
\hline $\begin{array}{l}\text { ME- } \\
\text { 48(anf) }\end{array}$ & 6.29 & 18.17 & 12.58 & 3.75 & 1.19 & 3.73 & 3.58 & 2.09 & 1.67 & 0.23 \\
\hline ME-88 & 15.90 & 35.10 & 19.40 & 4.91 & 1.31 & 5.63 & 5.71 & 3.06 & 2.12 & 0.30 \\
\hline PO-16A & 17.90 & 39.40 & 21.40 & 4.93 & 1.39 & 3.77 & 2.97 & 1.60 & 1.29 & 0.20 \\
\hline PO-61A & 25.40 & 52.10 & 24.00 & 4.73 & 2.05 & 3.81 & 2.67 & 1.36 & 1.01 & 0.17 \\
\hline PO-76 & 8.72 & 18.80 & 9.68 & 2.31 & 0.85 & 2.13 & 1.85 & 1.02 & 0.60 & 0.08 \\
\hline PO-98 & 7.73 & 9.91 & 9.88 & 2.95 & 1.08 & 3.49 & 3.93 & 2.42 & 2.06 & 0.33 \\
\hline PO-100A & 9.88 & 23.70 & 15.50 & 4.46 & 1.67 & 5.18 & 5.28 & 2.78 & 2.18 & 0.34 \\
\hline PO-102 & 6.93 & 16.90 & 12.50 & 4.02 & 1.42 & 4.89 & 5.38 & 3.49 & 3.29 & 0.51 \\
\hline PO-136A & 9.01 & 21.20 & 15.30 & 4.85 & 1.55 & 5.98 & 6.41 & 4.39 & 4.02 & 0.63 \\
\hline ME-1-61 & 14.00 & 36.10 & 18.10 & 4.24 & 1.48 & 4.03 & 3.86 & 2.17 & 1.70 & 0.25 \\
\hline
\end{tabular}

2 a 73 vezes o valor do condrito, exibindo acentuado enriquecimento dos ETRL em relação aos ETRP (razões $\mathrm{La}_{\mathrm{N}} / \mathrm{Eu}_{\mathrm{N}}=2,43-3,02, \mathrm{Gd}_{\mathrm{N}} / \mathrm{Lu}_{\mathrm{N}}=2,13-3,32, \mathrm{La}_{\mathrm{N}} /$
$\left.\mathrm{Lu}_{\mathrm{N}}=5,50-15,51\right)$, mostrando padrão de distribuição inclinado em relação ao condrito, semelhante ao padrão de basaltos tipo OIB (basaltos de ilhas oceânicas). Fra- 

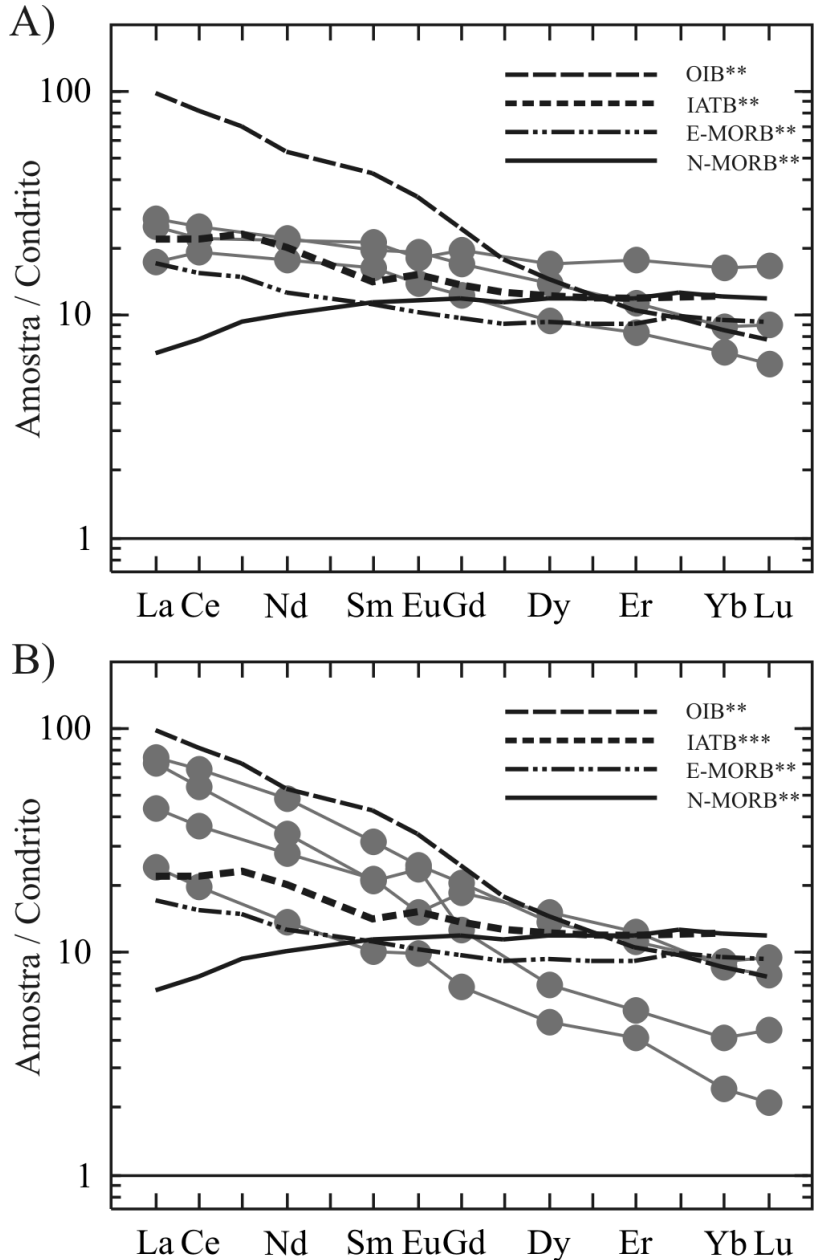

Figura 9 - Diagramas de ETR das rochas metamáficas analisadas e de basaltos de outros ambientes tectônicos normalizados pelo condrito*. (A) grupo 1, (B) grupo 2. $N$-MORB** = basalto normal de cadeia meso oceânica, E-MORB** = basalto enriquecido de cadeia meso oceânica, OIB** = basalto de ilha oceânica, IATB*** = basalto toleitico de arco de ilha. Valores compilados de: * Taylor \& McLennan (1985), ** = Sun \& McDonough (1989), $* * *=$ Wilson (1989).

cas anomalias positiva de európio $\left(\mathrm{Eu}^{*}=1,5-1,43\right)$ e negativa $\left(\mathrm{Eu}^{*}=0,76\right)$ são observadas nesse grupo.

A distribuição dos elementos traço (Tab. 2, Fig. 10) normalizados pelos valores de N-MORB (basaltos normais de cadeia meso-oceânica, Sun \& McDonough 1989) mostra que as rochas de ambos os grupos apresentam grande variação nos teores dos mesmos, exibindo concentrações de $\mathrm{Sr}, \mathrm{K}, \mathrm{Rb}, \mathrm{Ba}, \mathrm{Nb}, \mathrm{La}, \mathrm{Ce}$, $\mathrm{P}, \mathrm{Zr}$ e Sm mais elevados que o padrão de N-MORB. As amostras de grupo 2 apresentam maiores conteúdos em $\mathrm{Sr}, \mathrm{K}, \mathrm{Rb}, \mathrm{Ba}$, La, Ce e Sm em relação ao grupo 1, apresentando empobrecimento relativo de $\mathrm{Nb}$ e $\mathrm{Zr}$ em relação a Ba e ETR. A exceção é uma amostra desse grupo que apresenta padrão de distribuição semelhante ao grupo 1 (possui também os menores valores de ETR nesse grupo).
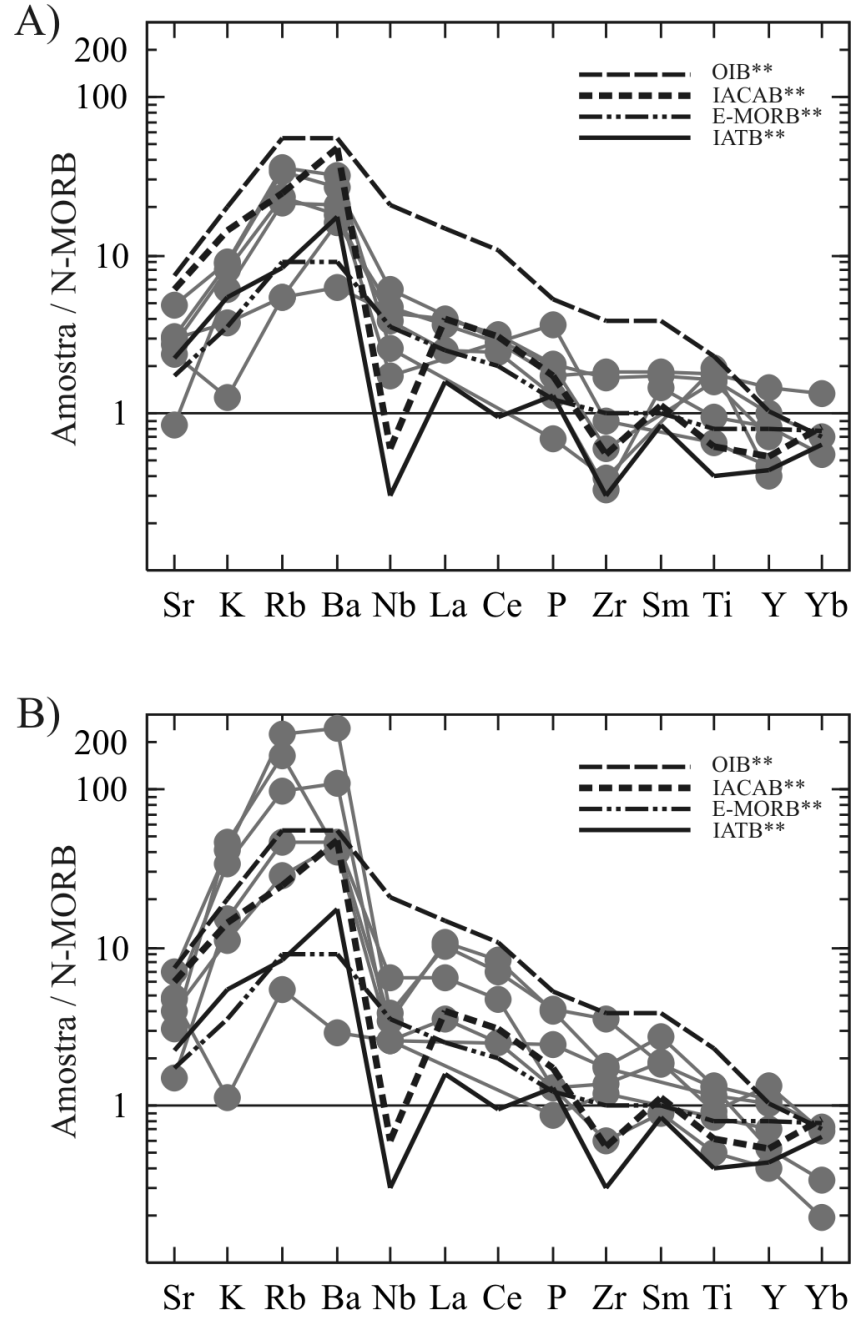

Figura 10 - Padrões de distribuição de elementos traços e La, Ce, Sm e Yb normalizados por NMORB (Sun \& McDonough 1989) para as amostras de metamáficas analisadas.

A comparação dos padrões de distribuição de elementos traço e ETR das amostras analisadas com os padrões de distribuição de E-MORB, N-MORB, OIB e IAB (Fig. 11) mostra que:

- o grupo 1 apresenta um padrão de distribuição semelhante ao E-MORB e ao IAB. O padrão de distribuição de ETR e de elementos traços, sugere que essas rochas são semelhantes principalmente a E-MORB;

- o grupo 2 apresenta um padrão de distribuição de ETR mais semelhante ao OIB, entretanto o padrão de distribuição de elementos traço e as leves anomalias negativas de $\mathrm{Nb}, \mathrm{Zr}$, e Ti; sugerem que essas rochas são mais semelhantes ao IAB.

Dados isotópicos Sm-Nd de três amostras de anfibolitos da região apresentam idades modelo $\mathrm{T}_{\mathrm{DM}}$ entre 1,0 e 1,23 (Tab. 4) e composições isotópicas similares às rochas do Arco Magmático de Goiás, mostrando que devem pertencer a essa unidade.

CONCLUSÕES Os padrões químicos de ETR e ele- 
A)

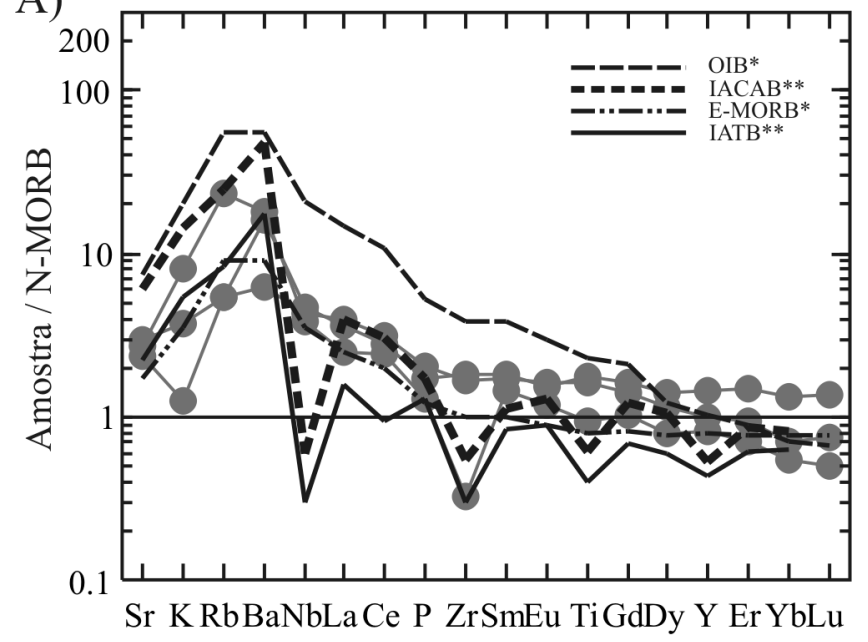

B)

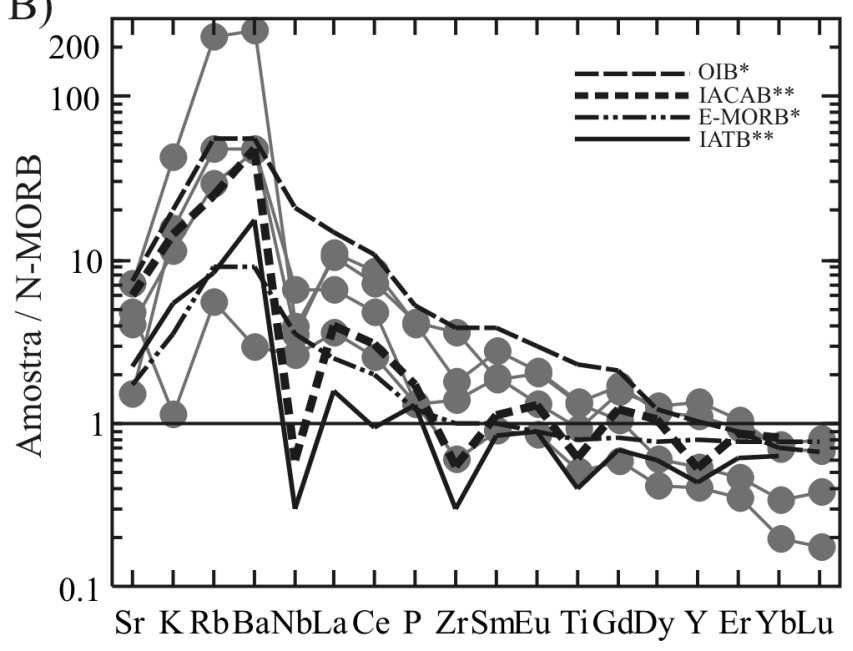

Figura 11 - Diagramas de concentrações normalizadas para elementos traços e ETR das rochas metamáficas analisadas e de basaltos de outros ambientes tectônicos normalizados por N-MORB*. (A) grupo 1, (B) grupo 2. E-MORB* = basalto enriquecido de cadeia meso oceânica, OIB* = basalto de ilha oceânica, IATB** = basalto toleítico de arco de ilha, IACAB** = basalto cálcio-alcalino de arco de ilha. Valores compilados de: * Sun \& McDonough (1989), ** Wilson (1989).

Tabela 4 - Dados Sm/Nd de três amostras de anfibolitos da região de Pontalina

\begin{tabular}{l|l|l|l|l|l|l}
\hline Amostras & $\mathrm{Sm}(\mathrm{ppm})$ & $\mathrm{Nd}(\mathrm{ppm})$ & ${ }^{147} \mathrm{Sm} /{ }^{144} \mathrm{Nd}$ & ${ }^{143} \mathrm{Nd} /{ }^{144} \mathrm{Nd}( \pm 2 \mathrm{SE})$ & $\mathrm{T}_{\mathrm{DM}}(\mathrm{Ga})$ & $\varepsilon_{(0)}$ \\
\hline ME-37 & 7,5 & 37,0 & 0,122 & $0,512445(06)$ & 1,00 & $-3,76$ \\
\hline PO-16A & 5,328 & 26,961 & 0,119 & $0,512372(21)$ & 1,08 & $-5,19$ \\
\hline PONT-4B* & 7,014 & 39,92 & 0,106 & $0,512164(12)$ & 1,23 & $-9,25$ \\
\hline
\end{tabular}

* Valores de Pimentel et al 2000a.

mentos traço observados nas amostras analisadas não são precisos na determinação do ambiente de formação dos protólitos das rochas. As amostras apresentam grande variação no conteúdo de elementos maiores e em parte traço, mostrando padrões de distribuição bastante aleatórios, com baixo grau de correlação entre si, não exibindo trends ou grupos bem definidos. Essa grande variação composicional em relação a elementos maiores e em parte traço, observada nas análises químicas, pode estar relacionada às transformações metamórficas anisoquímicas (muscovitização, epidotização, dentre outras) que as rochas foram submetidas. Os dados geoquímicos mostram que essas são de origem magmática e apresentam similaridade com basaltos toleíticos oceânicos, principalmente do tipo E-MORB, podendo haver contribuições de basaltos de arco e de basalto de ilha oceânica. O contexto geológico, a forma de ocorrência das rochas, e o padrão de distribuição de elementos traço sugerem, entretanto, que protólitos a partir de basaltos de ilha oceânica é menos provável.

Normalmente basaltos toleíticos gerados em ambiente de arco apresentam padrão de distribuição de elementos incompatíveis paralelo a subparalelo ao padrão de N-MORB (baixa abundância em Nb, La, $\mathrm{Ce}, \mathrm{P}, \mathrm{Zr}, \mathrm{Sm}$, Ti e Y), mostrando enriquecimento em $\mathrm{Sr}, \mathrm{K}, \mathrm{Rb}, \mathrm{Ba}$ e ETRL, e anomalias negativas de $\mathrm{Nb}$ e Ta (empobrecimento relativo em relação aos outros elementos traço), exibindo altas razões de $\mathrm{La} / \mathrm{Nb}$ em relação a basaltos N-MORB (Thompson et al. 1984, Wilson 1989). Comparando os padrões de basaltos cálcio-alcalinos de arco de ilhas com basaltos toleíticos de arco de ilhas, os basaltos cálcio-alcalinos mostram enriquecimento maior de $\mathrm{Sr}, \mathrm{K}, \mathrm{Rb}, \mathrm{Ba}, \mathrm{La}, \mathrm{Ce}$, $\mathrm{P}$ e Sm que basaltos toleíticos, entretanto $\mathrm{Nb}, \mathrm{Zr}, \mathrm{Ti}, \mathrm{Y}$ e $\mathrm{Yb}$ ainda limitam tendência relativamente achatada paralela ao padrão de N-MORB (Wilson 1989). Entretanto, graus diferentes de contaminação podem ocorrer em conseqüência de fluidos provenientes da subducção, de graus diferentes de fusão de metassedimentos e de crosta preexistente envolvida na subducção (Thompson et al. 1984, Wilson 1989). Dessa forma, é mais provável que a grande variação no conteúdo de 
elementos maiores, o padrão de distribuição de ETR semelhante a basaltos de ilha oceânica e o enriquecimento em elementos traço observados nas amostras sejam resultado de contaminação crustal de magmas gerados em ambientes de arco de ilha (subducção de crosta oceânica), desenvolvidos no Neoproterozóico, durante o processo de colisão entre as placas do São Francisco e Amazônica.

Agradecimentos Ao CNPq (processos $n^{\circ s} 140418 / 02-4$ e 303267/2002-0) e FAPESP (processo nos 2001-10034-2 e 2001/08456-6).

\section{Referências}

Cox K.G., Bell J.D. \& Pankhurst R.J. 1979. The Interpretation of igneous rocks. Allen G. \& Unwin, Londres, $450 \mathrm{p}$.

Hackspacher P.C., Trindade I.R., Fetter A.H., Dantas E.L. \& Santos B.L.C. 2004. Desenvolvimento das sistemáticas isotópicas $\mathrm{U}-\mathrm{Pb}$ e $\mathrm{Sm} / \mathrm{Nd}$ aplicadas em cronologia no Laboratório de Geoquímica Isotópica da UNESP - Rio Claro. In: CEPGeo-USP Simpósio 40 anos de Geocronologia no Brasil, Boletim de Resumos, São Paulo, p. 25.

Irvine T.N. \& Baragar W.R.A. 1971. A guide to the chemical classification of the common volcanic rocks. Canadian J. Earth Sci., 8:523-548.

Leake B.E. 1964. The chemical distinction between ortho- and para-amphibolites. J. Petrol., 5(2):238254.

Leake B.E., Woolley A.R., Arps C.E.S., Birch W.D., Gilbert M.C., Grice J.D., Hawthorne F.C., Kato A., Kisch H.J., Krivovichev V.G., Linthout K., Laird J.O., Mandarino J.A., Maresch W.V., Nickel E.H., Rock N.M.S., Schumacher J.C., Smith D.C., Stephenson N.C.N., Ungaretti L., Whittaker E.J.W. \& Youzhi G. 1997. Nomeclature of amphiboles: Report of the Subcommittee on Amphiboles of the International Mineralogical Association, Commission on New Minerals and Mineral Names. Am. Mineral., 82:1019-1037.

Miyshiro A. 1975. Volcanic rock series and tectonic setting. Ann. Rev. Earth Sci., 3: 251-269.

Niggli P. 1954. Rocks and mineral deposits. San Francisco: W.H. Freeman \& CO.

Pimentel M.M. \& Fuck R.A. 1991. Origin of orthogneiss and metavolcanic rock units in western Goiás: Neoproterozoic crustal accretion. Geoch. Bras., 5:133-152.

Pimentel M.M. \& Fuck R.A. 1992. Neoproterozoic crustal accretion in central Brazil. Geology, 20:375379.

Pimentel M.M., Fuck R.A. \&, Gioia S.M.C.L. 2000a. The neoproterozoic Goiás magmatic arc, central Brazil: A review and new Sm-Nd isotopic data. Rev. Bras. Geoc., 30:35-39.

Pimentel M.M., Fuck R.A., Jost H., Ferreira Filho C.F.
\& Araújo S.M. 2000b. The basament of the Brasilia Fold Belt and the Goiás Magmatic Arc. In: U.G. Cordani, E.J. Milani, A. Thomaz Filho \& D.A. Campos (eds.) Tectonic Evolution of South America. Rio de Janeiro, Brazil, p. 195-229.

Pimentel M.M., Jost H. \& Fuck R. A. 2004. O embasamento da Faixa Brasília e o Arco Magmático de Goiás. In: V. Mantesso-Neto, A. Bartorelli, C. Carneiro Dal Ré \& B.B. Brito Neves (org.) Geologia do Continente Sul-Americano: evolução da obra de Fernando Flávio Marques de Almeida, São Paulo, Ed. Beca. p. 335-368.

Richard L.R. 1995. Mineralogical and Petrological Data Processing System. MINPET for Windows. Version 2.02. Copyright 1988-1995.

Sun S.S. \& McDonough W.F. 1989. Chemical and isotopic systematics of oceanic basalts: implications for mantle composition and processes. In: Magmatismo in the ocean basins. Geological Society, Special Publication, v42, p. 313-345.

Taylor S.R. \& McLennan S.M. 1985. The continental crust: its composition and evolution. Blackwell: Oxford. 312 p.

Thompson R.N., Morrison M.A., Hendry G.L., Parry S.J., Simpson P.R., Hutchison R. \& O'Hara M.J. 1984. An assessment of the relative roles of Crust and Mantle in magma genesis: an elemental approach [and discussion]. Phil. Trans. R. Soc. Lond., A310:549-590.

Wilson M. 1989. Igneous Petrogenesis, a Global Tectonic Approach. Chapman \& Hall, London. 466 p.

Winchester J.A. \& Floyd P.A. 1977. Geochemical discrimination of different magma series and their differentiation products using immobile elements. Chem. Geol., 20:325-343.

Winchester J.A., Park R.G. \& Holland J.G. 1980. The geochemistry of Lewisian semipelitic schists from the Gairloch District, Wester Ross. Scott J. Geol., 16:165-179.

Manuscrito CSF-13

Submetido em 31 de maio de 2006 Aceito em 01 de março de 2007 